\title{
Exigência de sódio para poedeiras no final do primeiro ciclo e durante $o$ segundo ciclo de postura
}

\author{
Marcelo Luís Gomes Ribeiro',2, José Humberto Vilar da Silva², José Anchieta de Araujo ${ }^{3}$, \\ Terezinha Domiciano Dantas Martins ${ }^{2}$, Fernando Guilherme Perazzo Costa ${ }^{4}$, Patrícia Emília \\ Naves Givisiez ${ }^{4}$
}

1 Programa de Doutorado Integrado em Zootecnia - UFPBIUFRPEIUFC-CCAIAreia-PB. Bolsista do PICDT/Capes.

2 DAP/CFT/UFPB/Bananeiras/PB, CEP: 58.220.000. Bolsista PQ-CNPq.

${ }^{3}$ Mestrando em Zootecnia - DZ-CCA-UFPB-Campus III, Areia-PB.

${ }^{4}$ DZ-CCA-UFPB-Campus III, Areia-PB.

RESUMO - Dois experimentos foram realizados para estimar as exigências de sódio para poedeiras semipesadas no final do primeiro e durante o segundo ciclo de postura. O delineamento experimental foi o inteiramente casualizado, com sete níveis de sódio $(0,08 ; 0,13 ; 0,18 ; 0,23 ; 0,28 ; 0,33$ e $0,38 \%)$, cada um com seis repetições de seis aves no final do primeiro ciclo de postura e cinco repetições de seis aves no segundo ciclo de postura. No final do primeiro ciclo, não houve efeito dos níveis de sódio sobre o consumo de ração (CR), o peso dos ovos (PO), a conversão por dúzia de ovos (CDZ) e a gravidade específica (GE), mas a produção de ovos (PR), a massa de ovos (MO) e a conversão por massa de ovos (CMO) foram afetadas de forma quadrática. As exigências de sódio foram estimadas em 0,$21 ; 0,22$ e $0,21 \%$, respectivamente. No segundo ciclo, os níveis de sódio não tiveram efeito sobre o peso e a gravidade específica dos ovos, entretanto, influenciaram de forma quadrática a PR, MO, CMO e CDZ. Nesse ciclo, as exigências de sódio foram estimadas em 0,20;0,19;0,18 e 0,19\%, respectivamente. Considerando as estimativas de exigências de sódio pela produção de ovos e pela conversão por massa de ovos, sugerem-se 0,22 e $0,20 \%$ como níveis máximos de sódio, respectivamente, para o final do primeiro ciclo e para o segundo ciclo de postura.

Palavras-chave: bicarbonato de sódio, desempenho, minerais, qualidade da casca do ovo

\section{Sodium requirements for laying hens in the late first and during second egg-production cycle}

\begin{abstract}
Two experiments were carried out to estimate sodium requirements for brown-eggs laying hens in the late first and during second egg-production cycle. A completely randomized design was used, with seven sodium levels $(0.08,0.13,0.18,0.23,0.28,0.33$ and $0.38 \%)$, six replications of six birds in the late first egg-production cycle and five replications of six birds in the second egg-production cycle. In the late first egg-production cycle, sodium levels (SL) had no effect on feed intake (FI), egg weight (EW), egg dozen feed conversion (EDC) and egg-shell specific gravity (SG). The SL showed quadratic effect on egg production (EP), egg mass (EM) and egg mass feed conversion (EMC), that resulting in sodium requirements (SR) of $0.21,0.22$ and $0.21 \%$, respectively. In the second egg-production cycle, SL had no effect on EW and SG. However, EP, EM, EMC and EDC improved when the levels of sodium were 0.20, 0.19, 0.18 and $0.19 \%$, respectively. Considering the estimates of sodium requirements to egg production and egg mass feed conversion, could be suggests $0.22 \%$ e $0.20 \%$ as maximum sodium levels, respectively, to late first and second egg-production cycle.
\end{abstract}

Key Words: eggshell quality, mineral, performance, sodium bicarbonate

\section{Introdução}

A importância do sódio na manutenção das funções vitais do organismo está associada ao fato de este mineral ser o principal cátion presente nos fluidos extracelulares e atuar no equilíbrio ácido-básico e na pressão osmótica, na transmissão do impulso nas células nervosas e na pulsação do músculo cardíaco, assim como na permeabilidade celular e na absorção de monossacarídeos e aminoácidos (Guyton \& Hall, 1997).

Em estudo realizado por Begin \& Johnson (1976), a deficiência de sódio causou redução significativa na produção, no peso dos ovos, no consumo de ração e no peso corporal de poedeiras com 20 semanas de idade alimentadas

Este artigo foi recebido em 12/3/2007 e aprovado em 11/1/2008. Correspondências devem ser enviadas para marcelolgr@hotmail.com. 
durante 28 dias com ração contendo nível de sódio abaixo da exigência, enquanto Wideman \& Buss (1985) observaram que níveis elevados resultaram em aumentos significativos do consumo de água, da umidade das excretas e da excreção urinária de sódio, podendo causar distúrbios renais como urolítise.

Segundo Washburn (1982), a qualidade da casca do ovo é uma das preocupações na avicultura de postura, em virtude dos prejuízos econômicos associados à incidência de ovos com avarias de casca, uma vez que a incidência de quebra é de 6 a $8 \%$. Além disso, à medida que o lote de galinhas envelhece, observa-se redução simultânea na produção e na qualidade interna e externa dos ovos (Murakami et al., 2003).

Normalmente, poedeiras comerciais são criadas até 70 semanas, quando se encerra o primeiro ciclo de produção. Entretanto, em situações de maior oferta de ovos no mercado, de altos preços de ração e de pintainhas, de atrasos no fornecimento de pintainhas de 1 dia pelos incubatórios e de dificuldade financeira do produtor, uma boa opção para estender a vida produtiva das aves até 140 semanas de vida é a muda forçada (Silva et al., 2000).

As exigências de sódio são mais conhecidas para aves de primeiro ciclo. São escassos os trabalhos com aves de segundo ciclo de produção. O NCR (1994) e Rostagno et al. (2005) sugeriram, respectivamente, níveis de 0,15 e $0,23 \%$ de sódio na ração, considerando resultados de pesquisas realizadas apenas no primeiro ciclo de postura, assim como Murakami et al. (2000), que recomendaram 0,12\% de sódio para a mesma fase.

As recomendações de sódio para poedeiras durante o segundo ciclo de postura, além de escassas, são bastante discrepantes. Fassani et al. (2002) sugeriram valores de 0,19 a $0,22 \%$ de sódio, enquanto Murakami et al. (2003) propuseram $0,13 \%$ e Rodrigues et al. (2004), 0,25\% de sódio para esta fase.

Embora os efeitos do sódio sobre o equilíbrio ácidobase do organismo e sobre o desempenho de galinhas poedeiras durante o pico de postura tenham sido investigados, dados sobre os níveis de sódio no final do primeiro ciclo de postura e durante o segundo ciclo ainda são escassos. Este trabalho foi realizado com o objetivo de avaliar os efeitos dos níveis de sódio da ração sobre as exigências deste mineral no final do primeiro e durante o segundo ciclo de postura.

\section{Material e Métodos}

Foram realizados dois experimentos no Laboratório de Pesquisa em Nutrição de Aves (LPNA) do Centro de Formação de Tecnólogos (CFT-UFPB), Campus III, situado na cidade de Bananeiras-PB, microrregião do Brejo Paraibano.

Os ensaios tiveram duração de 224 dias e foram divididos em experimentos 1 e 2 para estimação das exigências de sódio para poedeiras no final do primeiro e durante o segundo ciclo de postura. No experimento 1 , foram utilizadas 252 poedeiras Lohmann Brown com 46 semanas de idade e peso vivo médio de $1,85 \mathrm{~kg}$ no final do primeiro ciclo de postura. O trabalho teve duração de quatro períodos de 28 dias. No experimento 2, foram utilizadas 210 aves, da mesma linhagem, com peso vivo médio de $1,88 \mathrm{~kg}$ pós-muda forçada com 75 semanas de idade.

As médias de temperatura e umidade relativa do ar, máxima e mínima, foram de 28,3 e $19,4^{\circ} \mathrm{C}$ e 86 e $53 \%$ para o experimento 1 e, 26,5 e $21,6^{\circ} \mathrm{C}$ e 95 e $53 \%$ para o experimento 2 e foram registradas utilizando-se termohigrômetro digital, às $9 \mathrm{~h}$ e $17 \mathrm{~h}$.

A muda forçada foi realizada fornecendo-se às aves água à vontade. O programa de luz foi suspenso do 10 ao $12 \underline{0}$ dia e retomado a partir do $13 \underline{0}$ dia com o aumento de 1 hora de luz artificial por semana até atingir 17 horas/dia (luz natural + artificial/dia). Esse programa foi mantido constante até o final da produção. A alimentação das aves do 1 o ao $12 \underline{o}$ dia foi feita com uma dieta de muda ( $25 \mathrm{~g} / \mathrm{ave} /$ dia) contendo $44 \%$ de milho, $45,6 \%$ de calcário, 7,2\% de fosfato bicálcico, $2,4 \%$ de sal, $0,4 \%$ de premix mineral e $0,4 \%$ de premix vitamínico, de acordo com Silva et al. (2003).

$\mathrm{Na}$ primeira semana pós-muda, a quantidade de ração fornecida foi de $25 \mathrm{~g} / \mathrm{ave} / \mathrm{dia}$ de ração de recria (13 a 18 semanas); na segunda semana, 40 g/ave/dia de ração pré-postura; na terceira semana, $60 \mathrm{~g} / \mathrm{ave} / \mathrm{dia}$ de ração de produção; e na quarta semana, $90 \mathrm{~g} / \mathrm{ave} / \mathrm{dia}$. $\mathrm{Na}$ quinta semana, o consumo foi voluntário e as coletas de dados foram iniciadas quando as aves atingiram $50 \%$ de produção.

Após a muda forçada, as aves foram selecionadas pelo peso vivo, alimentadas com uma dieta única durante 15 dias e novamente selecionadas pela produção de ovos. Aquelas com médias extremas de produção foram descartadas. $\mathrm{O}$ grupo de aves foi pesado e distribuído em pares por gaiolas de arame galvanizado $(33 \times 45 \mathrm{~cm})$, cada uma com um bebedouro nipple para cada quatro aves alojadas e um comedouro tipo calha na parte frontal. As gaiolas eram dispostas em fileiras duplas em galpão de $4 \times 28 \mathrm{~m}$, pé-direito de $1,8 \mathrm{~m}$ e cobertura com telhas de barro em duas águas. As duas fileiras duplas de gaiolas eram divididas por um corredor de $80 \mathrm{~cm}$ de largura.

Os experimentos foram realizados em delineamento inteiramente casualizado, com sete níveis de sódio $(0,08$; $0,13 ; 0,18 ; 0,23 ; 0,28 ; 0,33$ e $0,38 \%)$, cada um com seis 
repetições de seis aves (experimento 1) e cinco repetições de seis aves (experimento 2).

As rações experimentais, isonutritivas (Tabela 1), foram formuladas à base de milho e de farelo de soja para atender ou exceder as exigências nutricionais mínimas de poedeiras semipesadas com peso vivo igual ou superior a $1,85 \mathrm{~kg}$, em todos os nutrientes (Rostagno et al., 2005), exceto sódio, que foi suplementado com bicarbonato de sódio (27\% de sódio), em substituição a 0;0,204; 0,407; 0,611;0,815; 1,019 e $1,223 \%$ da areia lavada. Durante os dois experimentos, foram oferecidos $120 \mathrm{~g}$ de ração/ave/dia e água à vontade, cujo nível de sódio ( $40 \mathrm{mg} / \mathrm{L}$ ) foi determinado em análise. Em ambos os experimentos, as aves foram expostas a um programa de luz de 17 horas por dia.

O balanço eletrolítico da dieta-referência (126,3 mEq $\mathrm{kg}$ ) foi calculado segundo Mongin (1980).
Nos experimentos 1 e 2 foram avaliados a produção de ovos, o consumo de ração, o peso médio dos ovos, a massa de ovos, a conversão alimentar por massa de ovos, a conversão alimentar por dúzia de ovos e a gravidade específica em quatro subperíodos de 28 dias, de acordo com os níveis de sódio adicionados à ração.

A produção de ovos foi avaliada em porcentagem/ave/ dia, o consumo de ração, calculado pela diferença entre a ração fornecida e a sobra, e o peso médio dos ovos, considerando o peso de todos os ovos produzidos nos últimos cinco dias de cada um dos quatro subperíodos. A massa de ovos foi obtida pelo produto da porcentagem de ovos produzida e o peso médio dos ovos, enquanto a conversão alimentar por massa de ovos foi calculada pela relação entre a ração consumida pela massa de ovos produzida $(\mathrm{kg} / \mathrm{kg})$ e a conversão alimentar por dúzia de ovos, pela relação entre

Tabela 1 - Composição da ração-referência fornecida às aves durante a fase final do primeiro ciclo e durante o segundo ciclo de postura ${ }^{1}$

\begin{tabular}{|c|c|c|c|c|c|c|c|}
\hline \multirow[b]{2}{*}{ Ingrediente } & \multicolumn{7}{|c|}{ Nível de sódio (\%) } \\
\hline & 0,08 & 0,13 & 0,18 & 0,23 & 0,28 & 0,33 & 0,38 \\
\hline Milho, grão & 55,62 & 55,62 & 55,62 & 55,62 & 55,62 & 55,62 & 55,62 \\
\hline Farelo de soja & 23,48 & 23,48 & 23,48 & 23,48 & 23,48 & 23,48 & 23,48 \\
\hline Calcário & 9,70 & 9,70 & 9,70 & 9,70 & 9,70 & 9,70 & 9,70 \\
\hline Inerte ${ }^{2}$ & 5,02 & 4,82 & 4,61 & 4,41 & 4,16 & 4,00 & 3,80 \\
\hline Óleo vegetal & 3,90 & 3,90 & 3,90 & 3,90 & 3,90 & 3,90 & 3,90 \\
\hline Fosfato bicálcico & 1,55 & 1,55 & 1,55 & 1,55 & 1,55 & 1,55 & 1,55 \\
\hline DL-metionina $(99 \%)$ & 0,20 & 0,20 & 0,20 & 0,20 & 0,20 & 0,20 & 0,20 \\
\hline Cloreto de amônia & 0,18 & 0,18 & 0,18 & 0,18 & 0,18 & 0,18 & 0,18 \\
\hline Sal comum & 0,12 & 0,12 & 0,12 & 0,12 & 0,12 & 0,12 & 0,12 \\
\hline Premix vitamínico ${ }^{3}$ & 0,08 & 0,08 & 0,08 & 0,08 & 0,08 & 0,08 & 0,08 \\
\hline Cloreto de colina $\mathrm{a}^{3}$ & 0,07 & 0,07 & 0,07 & 0,07 & 0,07 & 0,07 & 0,07 \\
\hline Premix mineral ${ }^{4}$ & 0,05 & 0,05 & 0,05 & 0,05 & 0,05 & 0,05 & 0,05 \\
\hline $\mathrm{L}-$ lisina $\cdot \mathrm{HCl}$ & 0,02 & 0,02 & 0,02 & 0,02 & 0,02 & 0,02 & 0,02 \\
\hline Bicarbonato de sódio & 0,00 & 0,20 & 0,41 & 0,61 & 0,86 & 1,02 & 1,22 \\
\hline $\mathrm{BHT}^{5}$ & 0,01 & 0,01 & 0,01 & 0,01 & 0,01 & 0,01 & 0,01 \\
\hline Total & 100,00 & 100,00 & 100,00 & 100,00 & 100,00 & 100,00 & 100,00 \\
\hline \multicolumn{8}{|l|}{ Composição nutricional } \\
\hline $\mathrm{PB}(\%)^{6}$ & 18,00 & 18,00 & 18,00 & 18,00 & 18,00 & 18,00 & 18,00 \\
\hline EMAn $(\mathrm{kcal} / \mathrm{kg})^{1}$ & 2.750 & 2.750 & 2.750 & 2.750 & 2.750 & 2.750 & 2.750 \\
\hline Fósforo disponível ${ }^{1}$ & 0,38 & 0,38 & 0,38 & 0,38 & 0,38 & 0,38 & 0,38 \\
\hline $\mathrm{Ca}(\%)^{1}$ & 4,20 & 4,20 & 4,20 & 4,20 & 4,20 & 4,20 & 4,20 \\
\hline Metionina + cistina total $(\%)^{1}$ & 0,70 & 0,70 & 0,70 & 0,70 & 0,70 & 0,70 & 0,70 \\
\hline Metionina total $(\%)^{1}$ & 0,44 & 0,44 & 0,44 & 0,44 & 0,44 & 0,44 & 0,44 \\
\hline Lisina total $(\%)^{1}$ & 0,81 & 0,81 & 0,81 & 0,81 & 0,81 & 0,81 & 0,81 \\
\hline Treonina total $(\%)^{1}$ & 0,60 & 0,60 & 0,60 & 0,60 & 0,60 & 0,60 & 0,60 \\
\hline Triptofano total $(\%)^{1}$ & 0,19 & 0,19 & 0,19 & 0,19 & 0,19 & 0,19 & 0,19 \\
\hline $\mathrm{Cl}(\%)^{1}$ & 0,22 & 0,22 & 0,22 & 0,22 & 0,22 & 0,22 & 0,22 \\
\hline $\mathrm{Na}(\%)$ & 0,08 & 0,13 & 0,18 & 0,23 & 0,28 & 0,33 & 0,38 \\
\hline $\mathrm{Na}$ analisado $(\%)^{7}$ & 0,09 & - & - & - & - & - & - \\
\hline $\mathrm{K}(\%)$ & 0,60 & 0,60 & 0,60 & 0,60 & 0,60 & 0,60 & 0,60 \\
\hline $\mathrm{K}$ analisado $(\%)^{7}$ & 0,65 & - & - & - & - & - & - \\
\hline
\end{tabular}

${ }^{1}$ Recomendados por Rostagno et al. (2005).

2 Inerte = Areia lavada.

${ }^{3}$ Composição por kg do produto: vit. A - 10.000 .000 UI; vit. $D_{3}-2.500 .000$ UI; vit. E - 6.000 UI; vit. K - 1.600 mg; vit. $B_{12}-11.000$ mg; niacina - 25.000 mg;

ácido fólico - $400 \mathrm{mg}$; ácido pantotênico - $10.000 \mathrm{mg}$; Se - $300 \mathrm{mg}$; veículo q.s.p.

${ }^{4}$ Composição por kg do produto: Mn - 150.000 mg; Zn - 100.000 mg; Fe - 100.000 mg; Cu - 16.000 mg; I - 1.500 mg; veículo q.s.p.

${ }^{5} \mathrm{BHT}=$ butil-hidroxi-tolueno.

${ }^{6}$ Valor analisado no Laboratório de Controle de Qualidade de Alimentos.

7 Segundo Tedesco (1992). 
a quantidade de ração consumida $(\mathrm{kg})$ e as dúzias de ovos produzidas $(\mathrm{kg} / \mathrm{dz})$. A gravidade específica da casca dos ovos foi estimada utilizando-se dois ovos de cada parcela experimental no último dia de cada subperíodo, pelo método de flutuação dos ovos, em 17 soluções salinas, com densidade variando de 0,0025 , iniciando por 1,060 até $1,100 \mathrm{~g} / \mathrm{cm}^{3}$ (Baião, 1994).

As análises estatísticas foram realizadas utilizando-se o programa SAEG (Euclydes, 1982) e as médias dos tratamentos foram comparadas pelo teste $\mathrm{F}(\mathrm{P}<0,05)$. As exigências de sódio foram estimadas por regressão quadrática considerando o nível de significância, o valor do coeficiente de determinação e a resposta biológica das aves.

\section{Resultados e Discussão}

Não houve efeito significativo $(P>0,05)$ dos níveis de sódio sobre o consumo de ração, o peso dos ovos e a conversão alimentar por dúzia de ovos (Tabela 2). A produção de ovos, a massa de ovos e a conversão alimentar por massa de ovos melhoraram de forma quadrática $(\mathrm{P} \leq 0,05)$ nos níveis 0,$21 ; 0,22$ e $0,21 \%$, respectivamente, de sódio na ração (Tabelas 2 e 4; Figura 1). As regressões obtidas foram $\hat{\mathrm{Y}}=55,6915+172,595 \mathrm{X}-411,599 \mathrm{X}^{2} \quad\left(\mathrm{R}^{2}=0,74\right) ;$ $\hat{\mathrm{Y}}=34,1338+136,133 \mathrm{X}-312,405 \mathrm{X}^{2}\left(\mathrm{R}^{2}=0,76\right) \mathrm{e}$ $\hat{\mathrm{Y}}=2,89321-5,02724 \mathrm{X}+11,70200 \mathrm{X}^{2}\left(\mathrm{R}^{2}=0,50\right)$, que resultaram, respectivamente, em balanços eletrolíticos de 183,187 e $183 \mathrm{mEq} / \mathrm{kg}$. O resultado médio de $0,21 \%$ de sódio foi próximo do teor de $0,23 \%$ recomendado por Rostagno et al. (2005) e superior ao de $0,12 \%$ recomendado por Murakami et al. (2003) para poedeiras comerciais de primeiro ciclo de postura. Esses resultados contrariam a conclusão de Faria et al. (2000) de que níveis de sódio superiores a 0,16\% não têm efeito sobre o desempenho de poedeiras.

A produção de ovos (Figura 1A) foi menor nos maiores níveis de sódio, o que provavelmente está relacionado ao
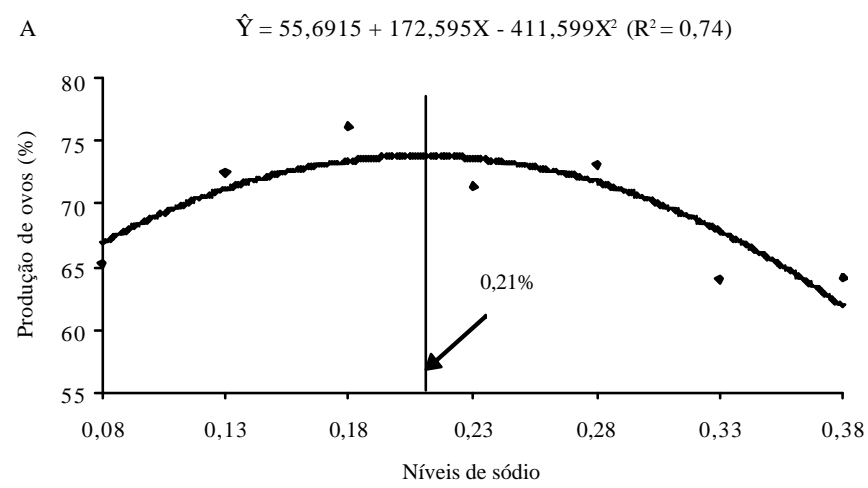

B

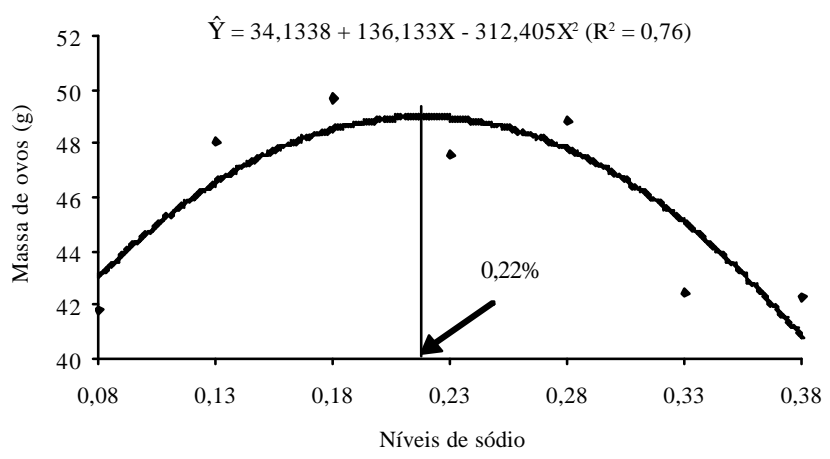

$\mathrm{C}$

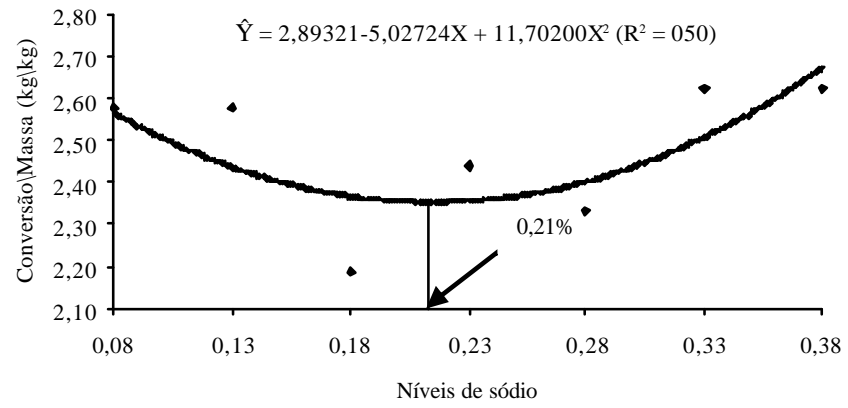

Figura 1 - Produção de ovos (A), massa de ovos (B) e conversão por massa de ovos (C) durante a fase final do primeiro ciclo de postura de acordo com os níveis de sódio das rações experimentais.

Tabela 2 - Consumo de ração (CR), produção de ovos (PR), peso dos ovos (PO), massa de ovos (MO), conversão por massa de ovos (CMO), conversão por dúzia de ovos (CDZ) e gravidade específica da casca dos ovos (GE) de poedeiras semipesadas alimentadas com rações contendo níveis crescentes de sódio (NS) na fase final do primeiro ciclo de postura

\begin{tabular}{|c|c|c|c|c|c|c|c|c|c|}
\hline & \multicolumn{7}{|c|}{ Nível de sódio na ração (\%) } & \multirow[b]{2}{*}{ Efeito } & \multirow[b]{2}{*}{$\mathrm{CV} \%$} \\
\hline & 0,08 & 0,13 & 0,18 & 0,23 & 028 & 0,33 & 0,38 & & \\
\hline CR (g/dia) & 105,88 & 122,04 & 108,09 & 114,71 & 112,05 & 110,79 & 108,97 & & \\
\hline PR (\%) & 65,22 & 72,54 & 76,20 & 71,29 & 73,09 & 64,05 & 64,10 & $* \mathrm{Q}$ & 11,33 \\
\hline PO (g) & 64,22 & 66,03 & 65,32 & 66,82 & 66,49 & 66,21 & 65,96 & $\mathrm{~ns}$ & 3,44 \\
\hline MO (g) & 41,88 & 47,90 & 49,77 & 47,64 & 48,60 & 42,41 & 42,28 & $* * \mathrm{Q}$ & 12,17 \\
\hline CMO (kg/kg) & 2,528 & 2,548 & 2,172 & 2,408 & 2,306 & 2,612 & 2,577 & $* \mathrm{Q}$ & 9,25 \\
\hline CDZ (kg/dz) & 2,576 & 2,679 & 2,670 & 2,638 & 2,629 & 3,198 & 3,111 & $\mathrm{~ns}$ & 19,25 \\
\hline $\mathrm{GE}\left(\mathrm{g} / \mathrm{cm}^{3}\right)$ & 1,090 & 1,089 & 1,088 & 1,087 & 1,088 & 1,088 & 1,088 & ns & 0,16 \\
\hline
\end{tabular}

ns = não-significativo $(P \geq 0,05)$.

$\mathrm{Q}=$ efeito quadrático ${ }^{*}(\mathrm{P} \leq 0,05) ;{ }^{* *}(\mathrm{P} \leq 0,01)$ 
impacto negativo da deficiência ou da toxidez do sódio sobre o desempenho das aves. Guyton \& Hall (1997) sugeriram que baixos níveis de sódio prejudicam a permeabilidade celular e a absorção de monossacarídeos e aminoácidos, principalmente lisina e arginina. Begin \& Johnson (1976) observaram que a produção, o peso dos ovos, o consumo de ração e o peso corporal de poedeiras foram afetados quando uma dieta de baixo teor de $\mathrm{NaCl}(0,0$ e $0,125 \%)$ foi fornecida às aves durante 28 dias.

McDowell (1992) descreveu que a deficiência de sódio afeta a utilização da energia e proteína da ração, enquanto o excesso desse mineral aumenta o consumo de água, a anorexia, a perda de peso, o edema, o nervosismo, a paralisia e uma variedade de sinais que dependem da espécie animal. Segundo esse autor, o nível máximo de sódio em rações para aves é de 0,79 ou $2 \%$ de $\mathrm{NaCl}$. Yoruk et al. (2000), no entanto, avaliaram a adição de bicarbonato de sódio na ração $(0,0$; 0,$1 ; 0,2 \mathrm{e} 0,4 \%$ ) de poedeiras no terço final do primeiro ciclo de postura (54 semanas) e concluíram que o aumento desta fonte de sódio na dieta diminuiu a taxa de mortalidade, melhorou a conversão alimentar e aumentou linearmente o consumo de ração e a produção de ovos.

A exigência de $0,21 \%$ de sódio estimada neste trabalho para aves no terço final de postura representa uma adição média de $0,48 \%$ de bicarbonato de sódio na ração, compatível com a recomendação de bicarbonato de sódio $(0,40 \%)$ para aumentar a tolerância de poedeiras ao estresse por calor nas horas de pico de temperatura.

Os piores resultados para massa e conversão por massa de ovos foram obtidos nos maiores níveis de sódio, portanto, não apenas a deficiência, como também o excesso, de sódio prejudicou o desempenho das aves. Segundo Underwood \& Suttle (1999), a ingestão contínua de rações com níveis insuficientes, ou com excesso, de sódio altera a concentração desse mineral nos tecidos e fluidos corporais, causando lesões bioquímicas e afetando as funções fisiológicas, o que ocasiona desordens metabólicas nas aves. Uma vez que o sódio ajuda a manter o equilíbrio ácido-básico (McDowell, 1992), o mesmo ocorre com o metabolismo protéico, energético e mineral, que afeta diretamente o desempenho das aves (Patence, 1990). Faria et al. (2000) conduziram um experimento com poedeiras leves com 60 semanas de idade para avaliar os efeitos dos níveis de sódio $(0,16 ; 0,20$ e $0,24 \%)$ e fósforo $(0,35 ; 0,45$ e $0,55 \%)$ e constataram que os níveis de sódio não influenciaram a massa e a conversão por massa de ovos.

A gravidade específica da casca do ovo (Tabela 2) não foi afetada significativamente pelos níveis de sódio da ração, o que está de acordo com os resultados obtidos por Junqueira et al. (2000) e Faria et al. (2000). Miles \& Harms (1982) afirmaram que a adição de bicarbonato de sódio na dieta melhorou a gravidade específica da casca dos ovos. Junqueira et al. (2003), trabalhando com diversas fontes e níveis de sódio em rações para poedeiras comerciais, também constataram melhora na gravidade específica dos ovos quando elevaram o nível de sódio da dieta de $0,17 \%$ para $0,28 \%$, independentemente do conteúdo de cloro ou da relação sódio/cloro.

Os níveis de sódio não tiveram efeito significativo $(\mathrm{P} \geq 0,05)$ sobre o peso e a gravidade específica da casca dos ovos (Tabela 3). Rodrigues et al. (2004), em experimento com poedeiras comerciais no segundo ciclo de postura, também não encontraram efeito significativo dos níveis de sódio sobre o peso dos ovos.

O consumo de ração aumentou até o nível de $0,23 \%$ de sódio na ração $(\mathrm{P} \leq 0,01)$ (Tabela 3; Figura 2). Segundo Silva et al. (2006), a falta e o excesso de sódio afetam a palatabilidade da ração, o que justifica o baixo consumo nos níveis extremos desse mineral. De acordo com Kuchinski et al. (1997), citados por Murakami et al. (2003), a deficiência de sódio em rações para poedeiras provoca redução no consumo de ração, portanto, segundo Silva et al. (2006), a retirada do cloreto de sódio é um método de muda forçada, pois provoca a rejeição da ração pelas aves.

Tabela 3 - Consumo de ração (CR), produção de ovos (PR), peso dos ovos (PO), massa de ovos (MO), conversão por massa de ovos (CMO), conversão por dúzia de ovos (CDZ) e gravidade específica da casca dos ovos (GE) de poedeiras alimentadas com rações contendo níveis crescentes de sódio durante o segundo ciclo de produção

\begin{tabular}{|c|c|c|c|c|c|c|c|c|c|}
\hline & \multicolumn{7}{|c|}{ Nível de sódio na ração (\%) } & \multirow[b]{2}{*}{ Efeito } & \multirow[b]{2}{*}{$\mathrm{CV} \%$} \\
\hline & 0,08 & 0,13 & 0,18 & 0,23 & 028 & 0,33 & 0,38 & & \\
\hline CR (g/dia) & 112,29 & 113,75 & 113,78 & 114,24 & 113,56 & 113,33 & 112,81 & & \\
\hline PR (\%) & 70,23 & 74,75 & 77,13 & 73,00 & 71,15 & 70,56 & 69,91 & $* * \mathrm{Q}$ & 1,31 \\
\hline PO (g) & 68,50 & 69,88 & 67,68 & 68,47 & 68,64 & 67,45 & 68,60 & $\mathrm{~ns}$ & 2,13 \\
\hline MO (g) & 48,11 & 52,24 & 52,20 & 49,98 & 48,84 & 47,59 & 47,96 & $* * \mathrm{Q}$ & 2,06 \\
\hline CMO $(\mathrm{kg} / \mathrm{kg})$ & 2,334 & 2,177 & 2,180 & 2,286 & 2,325 & 2,381 & 2,352 & $* * \mathrm{Q}$ & 1,95 \\
\hline CDZ (kg/dz) & 1,919 & 1,826 & 1,770 & 1,878 & 1,915 & 1,928 & 1,936 & $* * \mathrm{Q}$ & 1,23 \\
\hline $\mathrm{GE}\left(\mathrm{g} / \mathrm{cm}^{3}\right)$ & 1,086 & 1,085 & 1,086 & 1,082 & 1,081 & 1,083 & 1,081 & $\mathrm{~ns}$ & 0,20 \\
\hline
\end{tabular}

$Q=$ efeito quadrático ${ }^{* *}(P \leq 0,01) ; n s=$ não-significativo $(P \geq 0,05)$. 


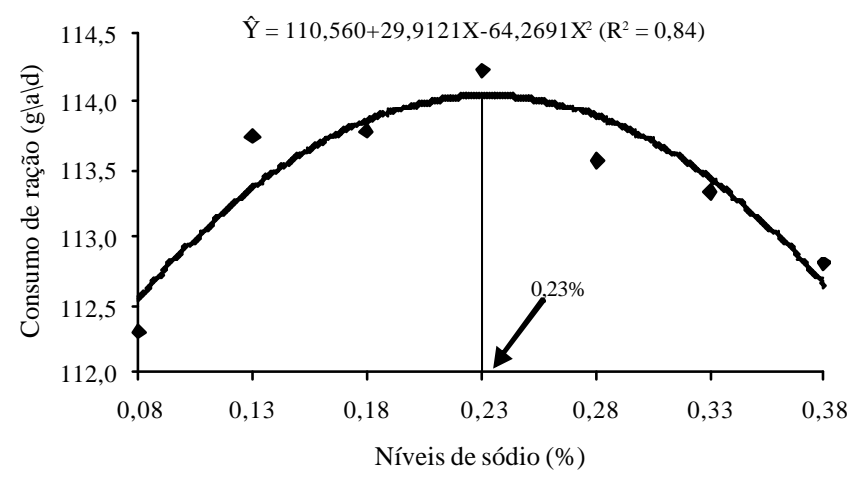

Figura 2 - Consumo de ração durante o segundo ciclo de postura de acordo com os níveis de sódio das rações experimentais.

A produção de ovos, a massa de ovos, a conversão alimentar por massa e a conversão alimentar por dúzia de ovos melhoraram de forma quadrática $(\mathrm{P} \leq 0,01)$ e podem ser representadas pelas equações: $\hat{\mathrm{Y}}=67,5278+68,2137 \mathrm{X}$ $172,087 \mathrm{X}^{2}\left(\mathrm{R}^{2}=0,54\right) ; \hat{\mathrm{Y}}=46,6425+46,7288 \mathrm{X}-124,662 \mathrm{X}^{2}$ $\left(R^{2}=0,59\right) ; \hat{Y}=2,37904-1,66892 X+4,75469 X^{2}\left(R^{2}=0,62\right)$ e $\hat{Y}=1,96113-1,26753 X+3,37528 X^{2}\left(R^{2}=0,50\right)$. As exigências de sódio foram estimadas, respectivamente, em 0,$20 ; 0,19 ; 0,18$ e $0,19 \%$ nos balanços eletrolíticos de 178 , 174,170 e $174 \mathrm{mEq} / \mathrm{kg}$, com média de $174 \mathrm{mEq} / \mathrm{kg}$ (Tabelas 3 e 4; Figura 3). As exigências de sódio foram menores que o nível de 0,23\% recomendado por Rostagno et al. (2005) para poedeiras comerciais durante o primeiro ciclo de postura e inferiores ao nível de $0,21 \%$ estimado no experimento 1 para o terço final de produção do primeiro ciclo.

O valor para balanço eletrolítico de $174 \mathrm{mEq} / \mathrm{kg}$ foi semelhante ao encontrado por Murakami et al. (2003) para poedeiras no segundo ciclo de postura e ao obtido por Fassani et al. (2002), que observaram maior taxa de produção de ovos no nível de $0,185 \%$ de sódio em pesquisa com poedeiras comerciais durante o segundo ciclo de postura.

Assim como no experimento anterior, com aves no final do primeiro ciclo de postura, o desempenho das aves no segundo ciclo foi influenciado tanto pela deficiência como pelo excesso de sódio na ração, o que reflete a importância de se balancear adequadamente o nível desse mineral nas dietas para permitir às aves atingir o máximo potencial de produção. O sódio, por atuar no controle da pressão osmótica, no equilíbrio acidobásico e na absorção de aminoácidos como lisina e arginina, de glicose e de vitaminas hidrossolúveis (Underwood \& Suttle, 1999; Murakami, 2000; Furlan et al., 2002), quando em desequilíbrio, afeta o desempenho das aves. Segundo Naber et al. (1984), a oferta de uma dieta com baixo teor de sódio $(0,046 \%)$ estabilizou a produção de ovos em duas semanas, aumentou a perda de peso das aves para $22 \%$ em três semanas e

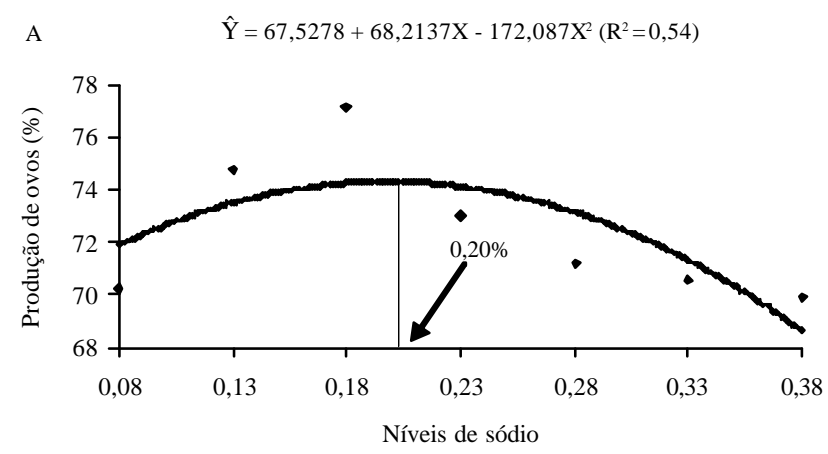

B
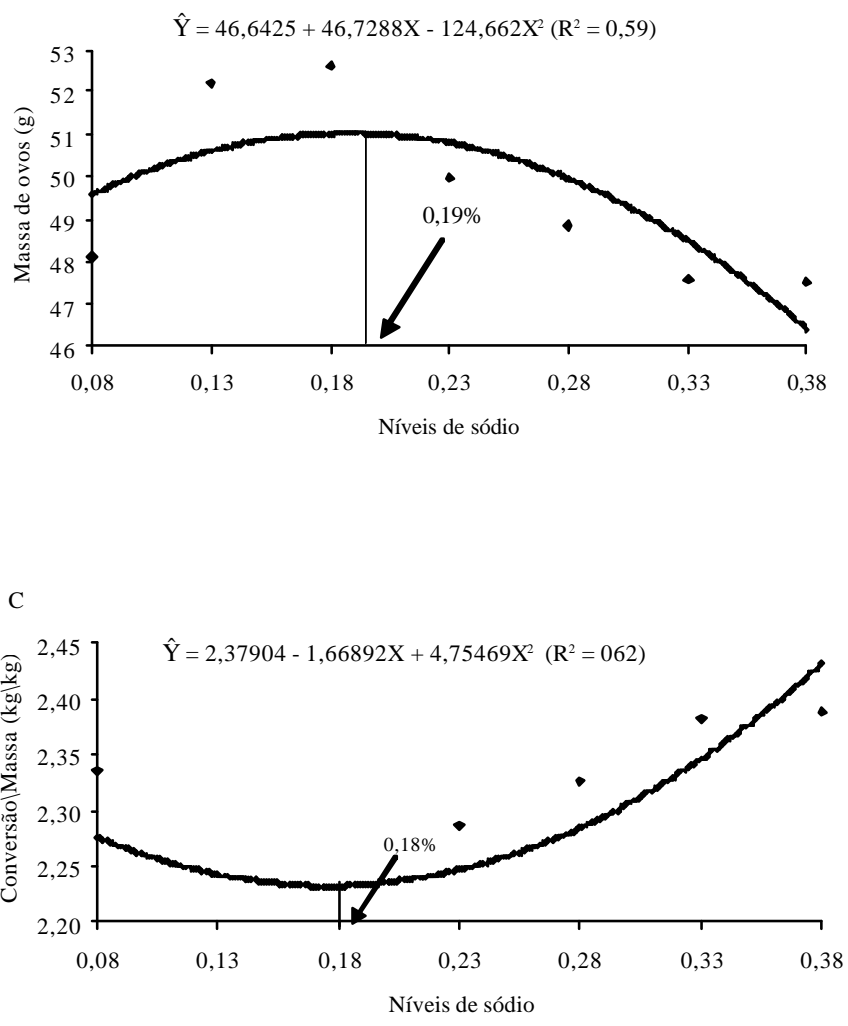

D

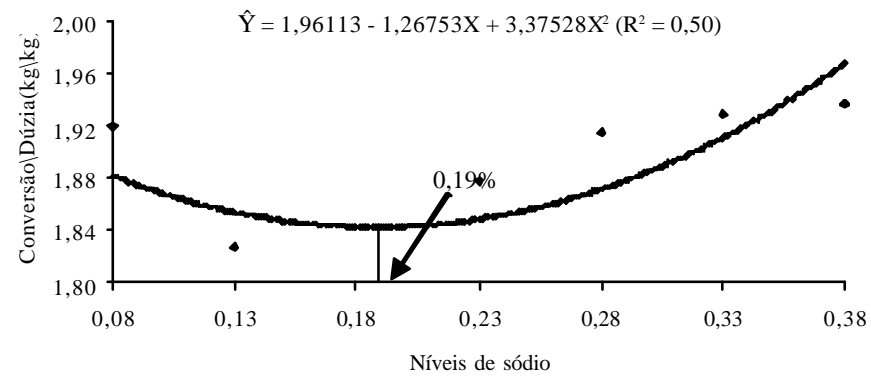

Figura 3 - Produção de ovos (A), massa de ovos (B), conversão por massa de ovos (C) e conversão por dúzia de ovos (D) no segundo ciclo de postura de acordo com os níveis de sódio das rações experimentais. 
reduziu o consumo de ração pela metade. Junqueira et al. (1984) também constataram diminuição na produção de ovos quando houve ingestão excessiva de sódio.

Rodrigues et al. (2004) realizaram experimento com poedeiras pós-muda forçada, aos 60 semanas de idade, e não encontraram efeito significativo dos níveis de sódio da ração sobre a massa de ovos e a conversão alimentar $(\mathrm{kg} / \mathrm{kg}$ e $\mathrm{kg} / \mathrm{dz}$ ). No entanto, resultado similar ao deste trabalho foi obtido por Fassani et al. (2002), em pesquisa com poedeiras comerciais durante o segundo ciclo de postura. Esses autores constataram efeito quadrático sobre a conversão alimentar $(\mathrm{kg} / \mathrm{kg})$ e determinaram o nível de $0,18 \%$ de sódio como o melhor nível para esta variável. Yoruk et al. (2000) constataram em poedeiras (54 semanas de idade) que a adição de bicarbonato de sódio na ração $(0,0 ; 0,1 ; 0,2$ e $0,4 \%)$ melhorou linearmente a conversão alimentar $(\mathrm{kg} / \mathrm{kg})$, enquanto Murakami et al. (2003) não notaram efeito significativo sobre esta variável e sobre a conversão por dúzia $(\mathrm{kg} / \mathrm{dz})$ em poedeiras no segundo ciclo de postura.
Semelhantemente ao resultado do primeiro ciclo, a gravidade específica não foi afetada pelos níveis de sódio da ração $(\mathrm{P}>0,05)$, o que confirma os resultados encontrados por Rodrigues et al. (2004), Murakami et al. (2003) e Fassani et al (2002). Entretanto, Junqueira et al. (1984) observaram maiores valores para essa característica quando as aves consumiram ração contendo $0,22 \%$ de sódio, enquanto Junqueira et al. (2003) observaram melhor gravidade específica quando aumentaram o nível de sódio de $017 \%$ para $0,28 \%$.

Entre o primeiro e segundo ciclos de postura, houve suave declínio na exigência de sódio (Tabela 4) quando consideradas a produção de ovos e a conversão por massa de ovos (redução de 0,22 para $0,20 \%$, respectivamente). A estimativa máxima de exigência de sódio para poedeiras variando de $0,22 \%$ durante o final do primeiro ciclo de postura e de $0,20 \%$ durante o segundo ciclo é compatível com as recomendações do NRC (1994) e de Rostagno et al. (2005) para poedeiras.

Tabela 4 - Recomendações de sódio (Na) e balanço eletrolítico da dieta (BED) obtidos pela produção de ovos (PR), massa de ovos (MO), conversão por massa de ovos (CMO) e conversão por dúzia de ovos (CDZ) no final do primeiro ciclo e durante o segundo ciclos de postura

\begin{tabular}{|c|c|c|c|c|}
\hline \multirow[b]{2}{*}{ Variável } & \multicolumn{2}{|c|}{10 ciclo } & \multicolumn{2}{|c|}{$2 \underline{0}$ ciclo } \\
\hline & $\mathrm{Na}(\%)$ & $\mathrm{BED}(\mathrm{mEq} / \mathrm{kg})$ & $\mathrm{Na}(\%)$ & $\operatorname{BED}(\mathrm{mEq} / \mathrm{kg})$ \\
\hline Produção de ovos (\%) & 0,21 & 183 & 0,20 & 178 \\
\hline Massa de ovos $(\mathrm{g})$ & 0,22 & 187 & 0,19 & 174 \\
\hline Conversão por massa $(\mathrm{kg} / \mathrm{kg})$ & 0,21 & 183 & 0,18 & 170 \\
\hline Conversão por dúzia (kg/dz) (EDC) & - & - & 0,19 & 174 \\
\hline Média & 0,21 & 184 & 0,19 & 174 \\
\hline
\end{tabular}

\section{Conclusões}

Considerando as estimativas de exigência de sódio pela produção de ovos e pela conversão por massa de ovos, sugerem-se 0,22 e 0,20\% como níveis máximos de sódio, respectivamente, para poedeiras no final do primeiro ciclo e no segundo ciclo de postura.

\section{Literatura Citada}

BAIÃO, N.C. Manejo de matrizes. Campinas: Fundação APINCO de Ciência e Tecnologia Avícola, 1994. p.81-82. (Coleção FACTA).

BEGIN, J.J.; JOHNSON, T.H. Effect of dietary salt on the performance of laying hens. Poultry Science, v.55, n.6, p.2395-2404, 1976.

FARIA, D.E.; JUNQUEIRA, O.M.; SAKOMURA, N.K. et. al. Efeito de diferentes níveis de sódio e fósforo sobre o desempenho e a qualidade da casca dos ovos de poedeiras comerciais. Revista Brasileira de Zootecnia, v.29, n.2, p.458-466. 2000.
FASSANI, E.J.; BERTECHINI, A.G.; BRITO, J.A.G. et al. Utilização de diferentes níveis de suplementação de sódio para poedeiras comerciais no segundo ciclo de produção. Revista Brasileira de Ciência Avícola, v.4, n.3, p.235-241, 2002.

FURLAN, R.L.; SILVA, A.V.F.; BORGES, S.A. et al. Equilíbrio ácidobásico. In: MACARI, M.; FURLAN, R.L.; GONZALES, E. (Eds.) Fisiologia aviária aplicada a frangos de corte. 2.ed. Jaboticabal: FUNEP, 2002. p.51-76.

GUYTON, A.C.; HALL, J.E. Tratado de fisiologia médica. Rio de Janeiro: Guanabara, 1997. 1014p.

JUNQUEIRA, O.M.; ANDREOTTI, M.O.; RODRIGUES, E.A. et al. Fontes e níveis de sódio em rações de poedeiras comerciais. Acta Scientiarum Animal Sciences, v.25, n.1, p.79-84, 2003.

JUNQUEIRA, O.M.; CAMARGO FILHO, B.; ARAÚJO, L.F. et al. Efeito das fontes e níveis de sódio, cloro e potássio e da relação $(\mathrm{Na}+\mathrm{K}) / \mathrm{Cl}$, sobre o desempenho e características do plasma sangüíneo de poedeiras comerciais. Revista Brasileira de Zootecnia, v.29, n.4, p.1110-1116, 2000.

JUNQUEIRA, O.M.; MILLES R.D.; HARMS R.H. Interrelationship between phosphorus, sodium and chloride in diet of laying hens. Poultry Science, v.61, n.6, p.1229-1236, 1984.

McDOWELL, L.R. Minerals in animal and human nutrition. London: Academic Press, 1992. 522p. 
MILES, R.D.; HARMS, R.H. Relationship between egg specific gravity and plasma phosphorus and sodium levels. Poultry Science, v.61, n.1, p.175-177, 1982.

MONGIN, P. Electrolytes in nutrition: a review of basic principles and practical application in poultry and swine. In: ANNUAL MINESOTTA CONFERENCE, 3., 1980, Illinois. Proceedings... Illinois: IMC, 1980. p.1-15.

MURAKAMI, A.E.; FIGUEIREDO, D.F.; PERUZZI, A.Z. et al. Níveis de sódio para poedeiras comerciais no primeiro e segundo ciclos de produção. Revista Brasileira de Zootecnia, v.32, n.6, p.1674-1680, 2003.

MURAKAMI, A.E. Balanço eletrolítico e sua influência sobre o desempenho dos ossos de frango. In. CONFERÊNCIA APINCO DE CIÊNCIA E TECNOLOGIA AVÍCOLA, 2000, Campinas. Anais... Campinas: Fundação Apinco de Ciência e Tecnologia Avícolas, 2000. p.33-61.

NARBER, F.C.; LATSHAW, J.D.; MARSH, G.A. Effectiveness of low sodium diets for recycling of production type hens. Poultry Science, v.63, n.12, p.2419-2429, 1984.

NATIONAL RESEARCH COUNCIL - NCR. Nutrient requirements of poultry. 9.ed. Washington, D.C.: National Academy Press, 1994. $155 \mathrm{p}$.

PATIENCE, J.F. A review of the role of acid-base balance in amino acid nutrition. Journal of Animal Science, v.68, n.2, 398-408, 1990.

RODRIGUES, E.A.; JUNQUEIRA, O.M.; VALÉRIO, M. et al. Níveis de sódio em rações de poedeiras comerciais no segundo ciclo de postura. Revista Brasileira de Zootecnia, v.33, n.2, p.391396, 2004.

ROSTAGNO, H.S.; ALBINO, L.F.T.; DONZELE, J.L. et al.Tabelas brasileiras de exigências nutricionais para aves e suínos (Composição de alimentos e exigências nutricionais). 2.ed., Viçosa, MG: Universidade Federal de Viçosa, 2005. 186p.
SILVA, J.H.V; RIBEIRO, M.L.G.; JORDÃO FILHO, J. et al. O sódio afeta o crescimento de órgãos dos sistemas circulatório, digestivo e imune de frangas. Revista Ave World, n.23, agostosetembro, 2006.

SILVA, J.H.V.; JORDÃO FILHO, J.; SILVA, E.L. Efeito do alho (Allium sativum Linn.), probiótico e virginiamicina antes, durante e após o estresse induzido pela muda forçada em poedeiras Semipesadas. Revista Braseleira de Zootecnia, v.32, n.6, p.1697-1704, 2003 (Supl. 1).

SILVA, J.H.V.; SANT OS, V.J. Efeito do carbonato de cálcio na qualidade da casca dos ovos durante a muda forçada. Revista Brasileira de Zootecnia, v.29, n.5, p.1440-1445, 2000.

TEDESCO, M.J. Extração simultânea de N, P, K, Ca e Mg em tecido de plantas por digestão com $\mathrm{H}_{2} \mathrm{O}_{2}-\mathrm{H}_{2} \mathrm{SO}_{4}$. Porto Alegre: Universidade Federal do Rio Grande do Sul, 1982. 23p.

EUCLYDES, R.F. SAEG - Sistema para análise estatística e genética. Viçosa, MG: Central de Processamento de Dados UFV - CPD, 1982. 59p.

UNDERWOOD, E.J.; SUTTLE, N.F. General introduction. In: UNDERWOOD, E.J.; SUTTLE, N.F. (Eds.) Mineral nutrition of livestock. London: CABI Publishing, 1999. p.1-16.

YORUK, M.A.; GUL, M.; KARAOGIU, M. Laying performance and egg quality of hens supplemented sodium bicarbonate during the later laying period. International Journal of Poultry Science, v.3, n.4, p.272-278, 2004.

WASHBURN, K.W. Incidence, cause and prevention of egg shell breakage in commercial production. Poultry Science, v.61, n.11, p.2005-2012, 1982.

WIDEMAN, R.E.; BUSS, E.G. Arterial blood gas, $\mathrm{pH}$ and bicarbonate values in laying hens for thin eggshell production. Poultry Science, v.64, n.5, p.1015-1019, 1985. 